\title{
Role of Vascular Endothelial Cell Growth Factor in Ovarian Hyperstimulation Syndrome
}

\author{
Ellis R. Levin, ${ }^{\star \ddagger}$ Gregory F. Rosen, ${ }^{\S}$ Denise L. Cassidenti, ${ }^{\S}$ Bill Yee, ${ }^{\S}$ David Meldrum,,${ }^{\S}$ Arthur Wisot, ${ }^{\S}$ and Ali Pedram ${ }^{\star \ddagger}$ \\ *Department of Medicine, the Long Beach Veterans Hospital, Long Beach, California 90822, and ${ }^{*}$ University of California, Irvine, \\ Irvine, California 92717, and the ${ }^{\S}$ Long Beach Memorial Medical Center and Centers for Advanced Reproductive Care, Long Beach, \\ California 90806 and Redondo Beach, California 90277
}

\begin{abstract}
Controlled ovarian hyperstimulation with gonadotropins is followed by Ovarian Hyperstimulation Syndrome (OHSS) in some women. An unidentified capillary permeability factor from the ovary has been implicated, and vascular endothelial cell growth/permeability factor (VEGF) is a candidate protein. Follicular fluids (FF) from 80 women who received hormonal induction for infertility were studied. FFs were grouped according to oocyte production, from group I (0-7 oocytes) through group IV (23-31 oocytes). Group IV was comprised of four women with the most severe symptoms of OHSS. Endothelial cell (EC) permeability induced by the individual FF was highly correlated to oocytes produced $\left(r^{2}=\right.$ $0.73, P<0.001)$. Group IV FF stimulated a $63 \pm 4 \%$ greater permeability than FF from group I patients $(P<0.01)$, reversed $98 \%$ by anti-VEGF antibody. Group IV fluids contained the VEGF165 isoform and significantly greater concentrations of VEGF as compared with group I $(1,105 \pm 87$ $\mathrm{pg} / \mathrm{ml}$ vs. $353 \pm 28 \mathrm{pg} / \mathrm{ml}, P<0.05)$. Significant cytoskeletal rearrangement of F-actin into stress fibers and a destruction of ZO-1 tight junction protein alignment was caused by group IV FF, mediated in part by nitric oxide. These mechanisms, which lead to increased EC permeability, were reversed by the VEGF antibody. Our results indicate that VEGF is the FF factor responsible for increased vascular permeability, thereby contributing to the pathogenesis of OHSS. (J. Clin. Invest. 1998. 102:1978-1985.) Key words: estrogen - vascular permeability • infertility • controlled ovarian hyperstimulation
\end{abstract}

\section{Introduction}

The Ovarian Hyperstimulation Syndrome (OHSS) ${ }^{1}$ is the collection of clinical findings that occur as the most serious complication resulting from the use of gonadotropins for ovulation induction (1). Although the mechanisms that lead to the development of the syndrome are not clearly understood, two major syndrome components are ovarian enlargement and increased vascular permeability. Increased vascular permeability leads to

Address correspondence to Ellis R. Levin, M.D., Long Beach Veterans Hospital, Medical Service (111-I), 5901 E 7th St., Long Beach, CA 90822. Phone: 562-494-2611 x5748; FAX: 562-494-5675; E-mail: elevin@pop.long-beach.va.gov

Received for publication 5 August 1998 and accepted in revised form 7 October 1998.

The Journal of Clinical Investigation

Volume 102, Number 11, December 1998, 1978-1985

http://www.jci.org extravasation of protein-rich fluid out of the intravascular space, and this can account for virtually all the manifestations of the syndrome. The signs include the accumulation of peritoneal (and rarely pleural or pericardial) fluid, edema, and hypovolemia, leading to anuria or hypotension in the most severe form (1-3). It has been postulated that a vasoactive substance is released from the ovary in response to hormonal stimulation and causes increased vascular permeability (2-4). Ovarian follicular fluid (FF) obtained from patients at risk for developing OHSS significantly augments in vitro permeability of endothelial cells (ECs) (5).

The substance responsible for inducing the manifestations of this syndrome has not been conclusively identified. One candidate as the responsible factor is vascular endothelial cell growth factor (VEGF). This glycoprotein was originally isolated as a vascular permeability factor (6) because it potently stimulates fluid transgression through EC tight junctions $(7,8)$. VEGF also is a mitogen for ECs (9), contributing to neovascularization in the ischemic diabetic retina (10) or tumor metastasis $(11,12)$. VEGF is secreted by a variety of cells and binds to several transmembrane receptors expressed on ECs, most importantly Flt and KDR (or VEGFR-1 and -2) $(13,14)$. This growth/ permeability factor is produced by normal and neoplastic human ovaries (15), including ovarian granulosa cells from women undergoing stimulation for in vitro fertilization (16).

In this study, we sought to identify VEGF as the factor contained in the FF from women undergoing hormonally induced oocyte production that induces EC permeability. We also characterized the cytoskeletal changes induced by the FF to provide a mechanistic basis for the increased EC permeability, which leads to the clinical manifestations of this syndrome.

\section{Methods}

Subjects. 80 female patients between the ages of 29 and 41 were studied; they were not receiving hormonal medications other than as prescribed by us for ovulatory induction. All gave informed consent to procurement and experimental use of their FF, as per the protocol approved by the Institutional Review Board of the Long Beach Memorial Medical Center. Using an unused aspiration cannula, each FF was obtained while a patient underwent transvaginal aspiration of follicles for in vitro fertilization. FF was obtained after hormone administration to stimulate oocyte production; the protocol included luteal phase administration of leuprolide acetate, $1 \mathrm{mg} / \mathrm{day}$, followed

1. Abbreviations used in this paper: BAEC, bovine aortic endothelial cell; bFGF, basic fibroblast growth factor; dpm, disintegrations per minute; EC, endothelial cell; ET-1, human endothelin-1; FF, follicular fluid; GC, granulosa cells; hCG, human chorionic gonadotropin; $\mathrm{hFSH}$, human follicle-stimulating hormone; L-NMMA, monomethyl L-arginine; NO, nitric oxide; OHSS, Ovarian Hyperstimulation Syndrome; VEGF, vascular endothelial cell growth factor. 
by daily administration of $150-450$ IU of human follicle-stimulating hormone (hFSH), based upon the women's age and past response history when applicable. Human chorionic gonadotropin (hCG), 10,000 IU, was administered 34-36 h before aspiration, and ovulation induction was monitored with vaginal ultrasound. The obtained fluid was not bloody, was not diluted, and was briefly centrifuged at low speed to remove debris or cells before freezing at $-70^{\circ} \mathrm{C}$ for subsequent assays within 1-2 mo. Fluids were subsequently grouped according to the number of oocytes retrieved: (group I, 0-7 oocytes; group II, 8-14; group III, 15-22; and group IV, 23-31). Patients underwent routine monitoring for signs of the development of OHSS.

Patients in groups I and II were asymptomatic for OHSS; in contrast, two patients in group III complained of significant "bloating and edema of their extremities," but this was not clinically apparent. Two additional patients in group III were noted on physical examination to have mild edema of their lower extremities but no evidence of ascites; their FFs induced the highest permeabilites in their group (see below). The edema responded to discontinuation of further hormonal induction and dietary salt restriction. The four patients that comprised group IV were the most symptomatic, developing moderately severe lower extremity edema in all and significant ascites in two patients. These patients were treated with discontinuation of hormonal induction and diuretics. All symptoms and signs resolved within $4 \mathrm{~d}$.

FF processing. Purification of $\mathrm{FF}$ for use in Western immunoblot and RIA was accomplished by affi-gel blue column, then desalting column elution, followed by dialysis against $20 \mathrm{mM}$ PBS for $12 \mathrm{~h}$. The resulting samples were concentrated fivefold by lyophilization, then reconstituted in water (immunoblot) or RIA buffer. Samples for immunoblot were pooled from four random patients in each group, except group IV (all samples used).

EC permeability assay. Bovine aortic ECs were isolated as previously described (17). BAEC formed a monolayer that displayed the typical EC cobblestone appearance and contact inhibition and uniformly tested positive for factor VIII-related antigen. Primary cultures of bovine aortic endothelial cells (BAEC), cultured in DMEM with $10 \%$ FBS, were seeded onto $0.45-\mu \mathrm{M}$ CM filters (Millipore, Bedford, MA) coated with rat tail collagen and contained within plastic inserts; the inserts were placed into 24-well plates and grown to confluence over $\sim 5 \mathrm{~d}$. $2 \mathrm{~d}$ after confluence, chambers were created by placing medium inside the inner insert and the outer wells, with the endothelial cell monolayer on the insert filter (18). The cells were washed and then subjected to $\mathrm{FF}$ incubation at $37^{\circ} \mathrm{C}$ in a $\mathrm{CO}_{2}$ incubator for $24 \mathrm{~h}$. FF was added to both aspects of the chamber, in unequal volumes, as explained below. After $24 \mathrm{~h}$, all medium was aspirated and discarded. To the apical surface (insert containing the cells on filter) was then added an experimental sample, containing $395 \mu$ l of FF, $4 \mu \mathrm{l}$ of $100 \mathrm{mM}$ mannitol, and $1 \mu \mathrm{l}$ of $\mathrm{H}^{3}$-mannitol $\left(1 \times 10^{6} \mathrm{cpm}\right)$. To the basolateral surface of the chamber (outer well), $600 \mu \mathrm{l}$ of FF was added. These specific volumes equalized fluid heights in the two chambers, so that only diffusive forces would be involved in permeability of the BAEC. Similar equalization occurred during the $24 \mathrm{~h}$ preceding the incubation period. After $2 \mathrm{~h}$ at $37^{\circ} \mathrm{C}$ in the incubator, flux rate was determined over $24 \mathrm{~h}$ by measuring the amount of $\mathrm{H}^{3}$ mannitol permeating to the basolateral compartment. This was determined by counting disintegrations per minute $(\mathrm{dpm})$ in the aspirated well fluid by using a $\beta$-counter. In some studies, we coadded antibodies that bind to either human endothelin-1 (ET-1; Peninsula Labs, Belmont, CA), VEGF, or basic fibroblast growth factor (bFGF; Santa Cruz Biotechnology, Santa Cruz, CA). In other experiments, exogenous VEGF (Upstate Biotechnology, Lake Placid, NY) was added to EC cultures or the nitric oxide (NO) synthase inhibitor, monomethyl L-arginine (10 $\mu$ M L-NMMA; CalBiochem, San Diego, CA) $30 \mathrm{~min}$ before the addition of FF. DMEM culture media alone (no serum or added peptides) was used for control permeability assessments.

Radioimmunoassay. VEGF immunoreactivity was measured by a double antibody, nonequilibrium assay carried out over $48 \mathrm{~h}$. VEGF was radiolabeled to a specific activity of $\sim 1,000 \mathrm{Ci} / \mathrm{mmol}$ by the iodogen method $(19,20)$. There was no cross-reactivity of the first antibody used in the assay with other peptides, including ET-1, atrial natriuretic peptide, angiotensin II, or bFGF. The sensitivity of the assay was $10 \mathrm{pg}$ per tube and the intra- and interassay coefficients of variation were $<10 \%$. Extraction efficiency of the VEGF in FF was $79.6-86 \%$ across all samples, and the values were accordingly corrected.

Western immunoblot. Follicular fluid $(5 \mathrm{ml})$ from each of four randomly selected patients in each of the groups (except IV) were processed, individually reconstituted, and aliquots from each sample $(20 \mu \mathrm{l})$ were pooled after reconstitution. Samples were processed as described above. Before separation by gel electrophoresis, the samples were not adjusted for protein because the permeability determinations on these same samples were also not adjusted for protein content, maintaining consistency.

Immunoprecipitation was performed on $100 \mu l$ of pooled, reconstituted samples from each group (20), by using a polyclonal VEGF antibody directed against the first 22 amino acids of N-terminal bovine VEGF. Immunoprecipitates were dissolved in SDS sample buffer, boiled, separated, and then transferred to nitrocellulose. VEGF protein was detected using the ECL Western blot kit (Amersham Life Sciences, Arlington Heights, IL), the first antibody at 1:500 dilution. Protein molecular weight markers and synthetic VEGF were run in parallel, bands were quantitated by laser densitometry, and the samples were used for a second, confirmatory immunoblot.

Cytoskeleton integrity. ECs were cultured to confluence on glass coverslips, then incubated with exogenous VEGF $(1 \mathrm{ng} / \mathrm{ml})$ or FF from group I or group IV patients for $24 \mathrm{~h}$, in the presence or absence of VEGF antibody. The cells were fixed with $3.75 \%$ formalin, washed, then followed by cold acetone fixation and permeabilization, and then stained with biotin-XX phalloidin (Molecular Probes, Eugene, OR); this demonstrated actin fibers, which are crucial to maintaining EC tight junctions (impermeability). In additional experiments, cells were pretreated with L-NMMA for $30 \mathrm{~min}$ before the addition of group IV FF.

ZO-1 protein was assessed by immunocytochemistry. ECs were grown to postconfluence, then fixed, permeabilized, and then stained with anti-ZO-1 antibody (Zymed Corp., San Francisco, CA). Secondary antibody conjugated to biotin was incubated, followed by the addition of FITC-strepavidin for purposes of fluorescent microscopic visualization of $\mathrm{ZO}-1$.

Statistical analysis. Individual or pooled patient data from the permeability assays were compared by ANOVA plus Scheffe's test, using the StatView statistical program $(P<0.05$ as significant). The same program was used to calculate correlation coefficients by linear regression analysis for oocyte production and EC permeability. VEGF concentrations were similarly analyzed and are expressed as the mean \pm SEM. Western immunoblots were compared by laser densitometry.

\section{Results}

Effects of follicular fluid on endothelial cell permeability. We first characterized our in vitro assay by its response to exogenously added VEGF. Incubation of the BAEC with VEGF, 1 $\mathrm{ng} / \mathrm{ml}$, significantly stimulated transgression of labeled mannitol across the endothelial cell barrier by $4 \mathrm{~h}$, and the maximum increase of $62 \%$ was seen at $24 \mathrm{~h}$, compared with the basal permeability $(0 \mathrm{~h})$, (basal permeability $6,206 \pm 63 \mathrm{cpm}, 24-\mathrm{h}$ permeability $10,073 \pm 81 \mathrm{cpm}, n=6$ per condition, $P<0.05)(\mathrm{Ta}-$ ble I). Permeability of the EC in the absence of VEGF increased by $\sim 7 \%$ over the $24 \mathrm{~h}$, and so the corrected increase in specific permeability at this time, induced by exogenous VEGF, was $55 \%$. Increased permeability stimulated by VEGF at $24 \mathrm{~h}$ was $97 \%$ prevented by coincubation with a monoclonal 
Table I. Effects of Exogenous VEGF on Endothelial Cell Permeability In Vitro

\begin{tabular}{ccc}
\hline & \multicolumn{2}{c}{ Permeability (dpm) } \\
\cline { 2 - 3 } & VEGF 1 ng/ml & DMEM (no VEGF) \\
\hline Time of cell incubation (h) & & \\
0 & $6206 \pm 63$ & $6096 \pm 48$ \\
2 & $7133 \pm 131$ & $6138 \pm 70$ \\
4 & $7795 \pm 31^{*}$ & $6321 \pm 86$ \\
8 & $8934 \pm 91^{*}$ & $6484 \pm 65$ \\
24 & $10073 \pm 81^{*}$ & $6566 \pm 48$ \\
VEGF concentration (ng/ml) & & \\
No peptide & $6114 \pm 12$ & \\
0.1 & $6191 \pm 36$ & \\
0.5 & $7189 \pm 153$ & \\
1 & $10483 \pm 160^{*}$ & \\
2 & $11314 \pm 186^{*}$ & \\
& & \\
\hline
\end{tabular}

Data represent the combined results from two experiments, each done in triplicate ( $n=6$ observations per condition) and are the mean \pm SEM. $* P<0.05$ by ANOVA plus Scheffe's F-test for condition vs. $0 \mathrm{~h}$ or vs. no VEGF peptide added to the cells. Hour 0 indicates the basal permeability of the endothelial cells before the addition of VEGF. Bottom data set represents the permeabilities induced by exogenous VEGF at $24 \mathrm{~h}$.

antibody to this growth factor, diluted to 1:100 (data not shown). In dose-related fashion, VEGF caused a significant increase in endothelial cell permeability. Increased permeability was first observed at a concentration of $0.5 \mathrm{ng} / \mathrm{ml}$ at $24 \mathrm{~h}$, but a substantial increase of $71 \%$ was seen at $1 \mathrm{ng} / \mathrm{ml}$ of VEGF (Table I).

We then examined the permeabilities induced by the FF. The induced permeabilities positively correlated with the number of oocytes produced by the individual patients (Fig. $1 \mathrm{~A}$ ) (correlation coefficient, $r^{2}=0.71, P<0.001$ ). 15 of the individual patients overlapped and hence are not represented as discrete circles on the figure. Comparable correlation was seen when the patients were represented as group mean oocyte production (Fig. $1 B)\left(r^{2}=0.73, P<0.001\right)$. The values for each group are shown in Table II. Women who produced 15-22 oocytes had a mean permeability of 7,954 cpm, which was significantly increased from group I by $30 \pm 3 \%$, while group IV fluids (23-31 oocytes) induced a $63 \pm 4 \%$ increase in permeability $(P<0.01)$. The significantly increased permeability induced by the FF from the group IV patients correlated to their development of edema or ascites. Follicular fluids from women producing 8-14 oocytes (group II) produced a permeability modestly greater (14\%) than group I fluids (0-7 oocytes), and women in both groups were asymptomatic.

Identification of VEGF as the permeability factor. We then sought to determine the identity of the permeability factor in the FF, theorizing that VEGF was the best candidate based upon existing studies. We coincubated the endothelial cells with pooled FF from group III or IV patients and an antibody that binds human VEGF. The VEGF antibody reversed the mean FF-stimulated permeabilities (above those of group I) by 95 and $98 \%$, respectively (Table II) $(P<0.05$ compared with group III or IV FF alone). In contrast, antibody to human ET-1 or bFGF caused an insignificant reversal. These specific-

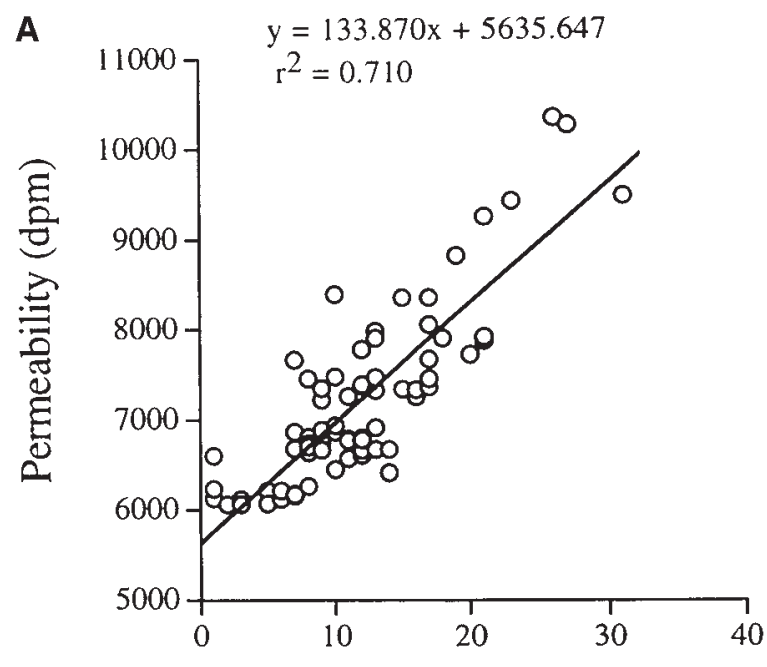

\section{Oocyte number}

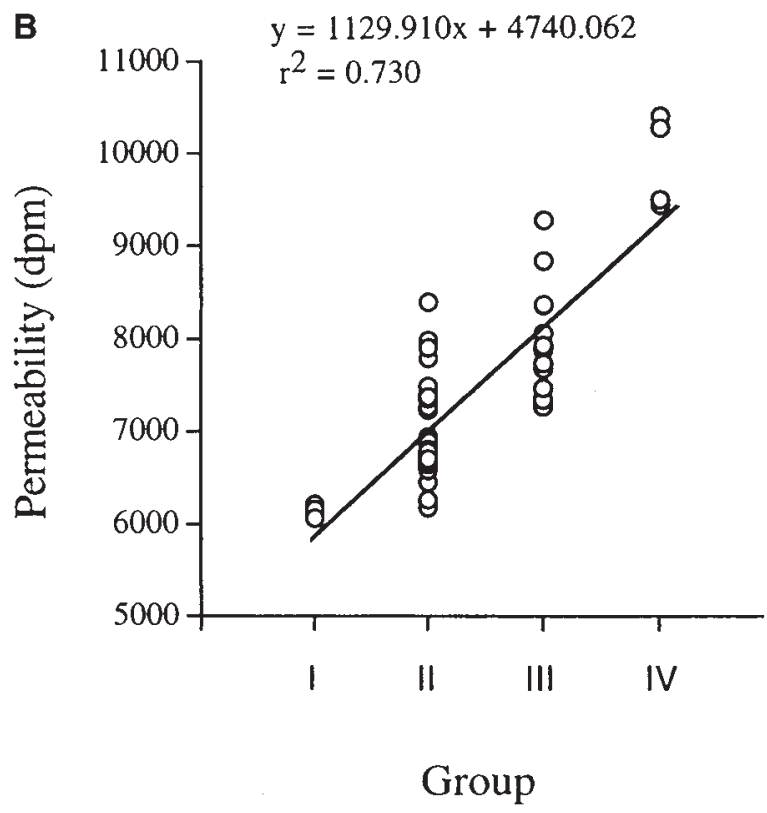

Figure 1. (A) Correlation of number of oocytes retrieved from women after hormonal stimulation of the ovary with in vitro endothelial cell permeability stimulated by their individual ovarian FF. Each circle represents the permeability to mannitol that transgresses an endothelial cell monolayer in culture at $24 \mathrm{~h}$, as described in Methods, as a function of the number of oocytes produced. FF samples from 80 women were studied, but only 65 discrete circles are shown because of overlapping values. $(B)$ Group correlations for oocyte production and FF-induced permeability. Some patient values overlap and hence are not shown as discrete circles.

ity controls were used because ET-1 and bFGF have been identified to stimulate increased vascular permeability in some situations. Similarly, nonspecific human IgG antibody did not affect the group IV-induced permeability (data not shown).

The ability of VEGF to enact increased cell growth or other actions is felt to be mediated at least in part by the generation of NO (21). To determine a possible role for NO in the action of FF, L-NMMA was added before FF or exogenous VEGF addition. The increased permeability stimulated by 
Table II. Stimulation of In Vitro Endothelial Cell Permeability by Follicular Fluids and Reversed by VEGF Antibody

\begin{tabular}{|c|c|c|c|c|c|c|}
\hline \multirow[b]{2}{*}{ Group } & & \multirow{2}{*}{$\begin{array}{l}\text { Oocyte } \\
\text { number }\end{array}$} & \multicolumn{4}{|c|}{ Permeability (cpm) } \\
\hline & & & $\mathrm{FF}$ & $\mathrm{FF}+\mathrm{VEGFab}$ & $\mathrm{FF}+\mathrm{ET}-1 \mathrm{ab}$ & $\mathrm{FF}+\mathrm{bFGFab}$ \\
\hline $\mathrm{C}$ & - & - & $6008 \pm 28$ & - & - & - \\
\hline I & 11 & $0-7$ & $6130 \pm 18$ & - & - & - \\
\hline II & 50 & $8-14$ & $6963 \pm 68^{*}$ & - & - & - \\
\hline III & 15 & $15-22$ & $7954 \pm 156 *$ & $6436 \pm 51^{\ddagger}$ & $7903 \pm 103 *$ & - \\
\hline IV & 4 & $23-31$ & $10014 \pm 294 *$ & $6252 \pm 45^{\ddagger}$ & $9846 \pm 68 *$ & $9751 \pm 77 *$ \\
\hline
\end{tabular}

Permeability data for each group are the mean \pm SEM. The permeability induced by the FF from individual patients reflected duplicate in vitro determinations for each patient's sample assessed at 24 h. $n$ is the number of individual patients within each group. $* P<0.05$ vs. permeability induced by group I FF. ${ }^{\ddagger} P<0.05$ for FF vs. FF plus VEGF antibody. C, control media (no FF); FF, follicular fluid; ab, antibody; ET-1, endothelin-1; bFGF, basic fibroblast growth factor.

group IV FF was reversed $52 \%$ by inhibition of NO synthase (Table III). Similarly, exogenous VEGF-stimulated permeability was reversed $47 \%$ by this inhibitor of NO production.

Detection and quantitation of VEGF in FF. We determined both qualitatively and quantitatively the VEGF contained in the FFs. Known amounts of exogenous human VEGF165 were separated on gel in parallel with the patient samples; all samples were membrane transferred and immunoblotted with the growth factor antibody. Exogenous VEGF produced an expected single discrete band, in dose-related fashion, which was $\sim 23 \mathrm{kD}$ in size as a monomer (Fig. 2). This corresponds to the gel migration of endogenous VEGF165 detected in vascular smooth muscle cells (22). A single, same-sized band was detected in the FF samples, indicating that the 165-amino acid isoform of VEGF predominates in the ovary. In groups I or II, little VEGF was detected. In contrast, the samples from the women producing $>23$ oocytes (group IV) had clearly detectable VEGF protein, and the VEGF band density correlated with the degree of ovarian stimulation (oocyte number). The density of the VEGF band from group IV samples was roughly comparable with that produced by $100 \mathrm{pg}$ of exogenous VEGF.

To precisely determine the concentration of VEGF in the FFs, we developed an RIA for the growth/permeability factor.

Table III. Reversal of Endothelial Cell Permeability by NO Synthase Inhibition

\begin{tabular}{llc}
\hline \multirow{2}{*}{ Group } & \multicolumn{2}{c}{ Permeability (dpm) (\% of control) } \\
\cline { 2 - 3 } & L-NMMA & + L-NMMA \\
\hline Control & 100 & $101 \pm 3$ \\
FF Group IV & $161 \pm 3^{*}$ & $128 \pm 6^{\ddagger}$ \\
VEGF 1 ng/ml & $164 \pm 4^{*}$ & $134 \pm 2^{\ddagger}$
\end{tabular}

Data are the mean \pm SEM permeability for each treatment (six replications per condition) carried out for $24 \mathrm{~h}$ and are derived from three experiments. FF or VEGF data are compared with permeability from control EC in DMEM in the absence of any FF added to the chambers. $* P<$ 0.05 for permeability induced by FF or VEGF vs. permeability of control EC. ${ }^{\ddagger} P<0.05$ for FF or VEGF vs. FF or VEGF + L-NMMA, $10 \mu \mathrm{M}$.

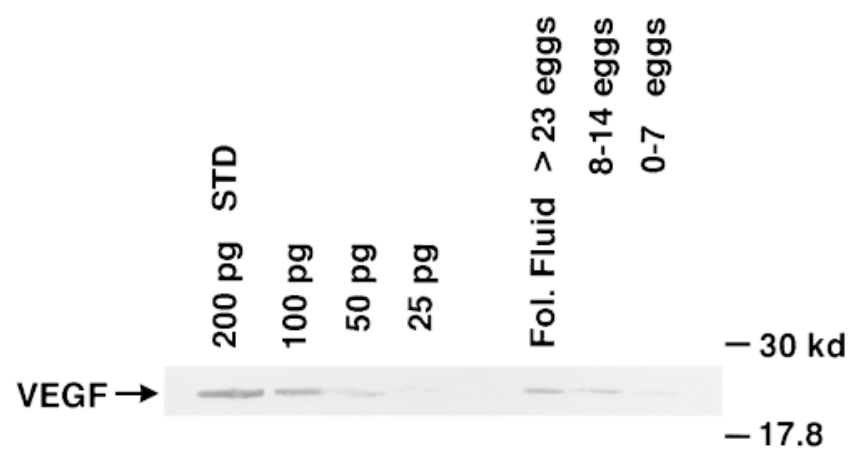

Figure 2. Immunoblot of VEGF contained within the FF of women undergoing ovarian stimulation by hormonal administration. Lanes are exogenous VEGF $(200,100,50$, and $25 \mathrm{pg})$ and pooled FF from groups IV ( $>23$ oocytes), II, and I, respectively. Molecular weight markers run in parallel during gel separation are shown on the right side of the figure.

As seen in Fig. 3, VEGF concentrations from the four groups progressively increased. Group I patients had a mean VEGF value of $353 \pm 28 \mathrm{pg} / \mathrm{ml}$, increased to a mean of $511 \pm 46 \mathrm{pg} / \mathrm{ml}$ in group II $(P<0.05)$. Group III patients had a mean VEGF concentration of $805 \pm 62 \mathrm{pg} / \mathrm{ml}$, and group IV patients had threefold the VEGF level of group I, at $1105 \pm 87 \mathrm{pg} / \mathrm{ml}$. The values obtained by RIA correlated well with oocyte produc-

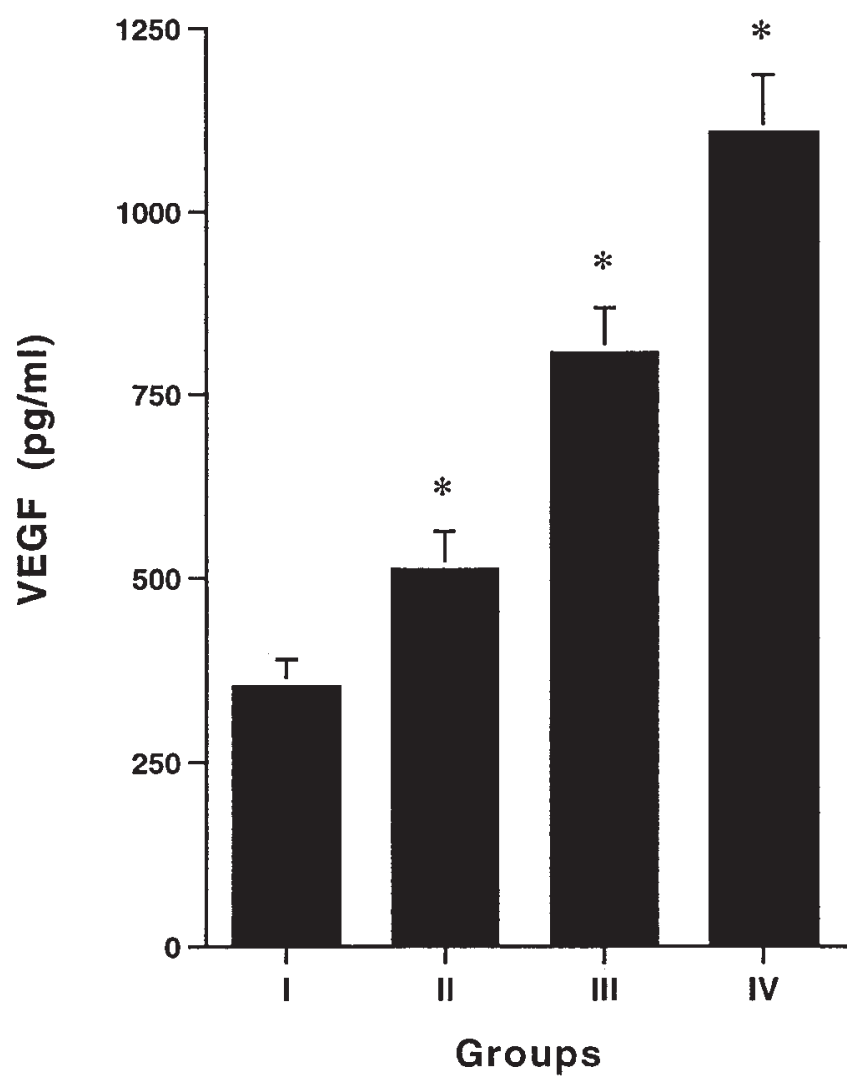

Figure 3. VEGF concentration in the follicular fluids of patients in groups I-IV. Each bar is the mean \pm SEM of the samples in the group. Asterisks indicate $P<0.05$ by ANOVA plus Scheffe's F-test vs. group I. 
tion and generally paralleled the results from Western immunoblot, which is not quantitative.

Cytoskeletal rearrangement induced by group IV FF. We then assessed the mechanism that leads to increased EC permeability. ECs form tight junction associations, regulating the bidirectional passage of ions, nutrients, and fluids through the endothelial lining (23). This limits the transgression of fluid and protein out of the intravascular space to the peripheral tissues. One important regulatory mechanism for the integrity of tight junction maintenance is distribution of actin to a cortical (peripheral) pattern, precluding stress fiber formation. This situation is demonstrated by EC cultured on glass coverslips in DME and stained to show F-actin (Fig. $4 a, A$ ). A similar pattern of peripheral actin fiber localization in the cell is seen when ECs are incubated with FFs from group I patients (Fig. 4 $a, B)$. In contrast, incubation of the cells with either group IV FF $(C)$ or exogenous VEGF $(D)$ caused a marked redistribution of actin fibers to transversely span the entire cell, with resulting stress fiber formation. Actin redistribution induced by either exogenous VEGF or group IV FF was substantially reversed by coincubation with VEGF antibody ( $E$ and $F$, respectively). This indicated that the VEGF content of the group IV FF was responsible for this architectural change within the EC, leading to increased vascular permeability.

Since we found that NO contributed to the increased permeability stimulated by group IV FF or exogenous VEGF, we assessed its contribution to the redistribution of actin. We found that L-NMMA significantly reversed the effect of the group IV FF to stimulate stress fiber formation (Fig. $4 b$ ). These results provide a mechanism to understand the contribution by NO to the permeability enhancing action of the group IV FF.

We also examined the integrity of ZO-1 tight junction protein alignment at the borders of the apposed EC (Fig. 5). The distribution of ZO-1 at the borders is known to be discontinuous around the normal EC (24), as seen in $A$. Group I FF had no effect on this pattern $(B)$. Group IV FF or exogenous VEGF each induced significant clumping and disruption of the ZO-1 tight junction protein ( $C$ and $D$ ), often leaving large gaps in ZO-1 expression (arrowheads). The disruption highly correlates with increased cell permeability (25). Coincubation of the cells with VEGF ab again substantially reversed the effects of either FF $(E)$ or exogenous VEGF $(F)$. This indicates an additional mechanism by which the VEGF in FF disrupts the integrity of EC tight junctions, leading to increased permeability.

\section{Discussion}

The symptoms that comprise the Ovarian Hyperstimulation Syndrome are felt to mainly result from the leakage of fluid from capillaries stimulated by an ovary-derived permeability factor. It is proposed that production of this factor is aug- a
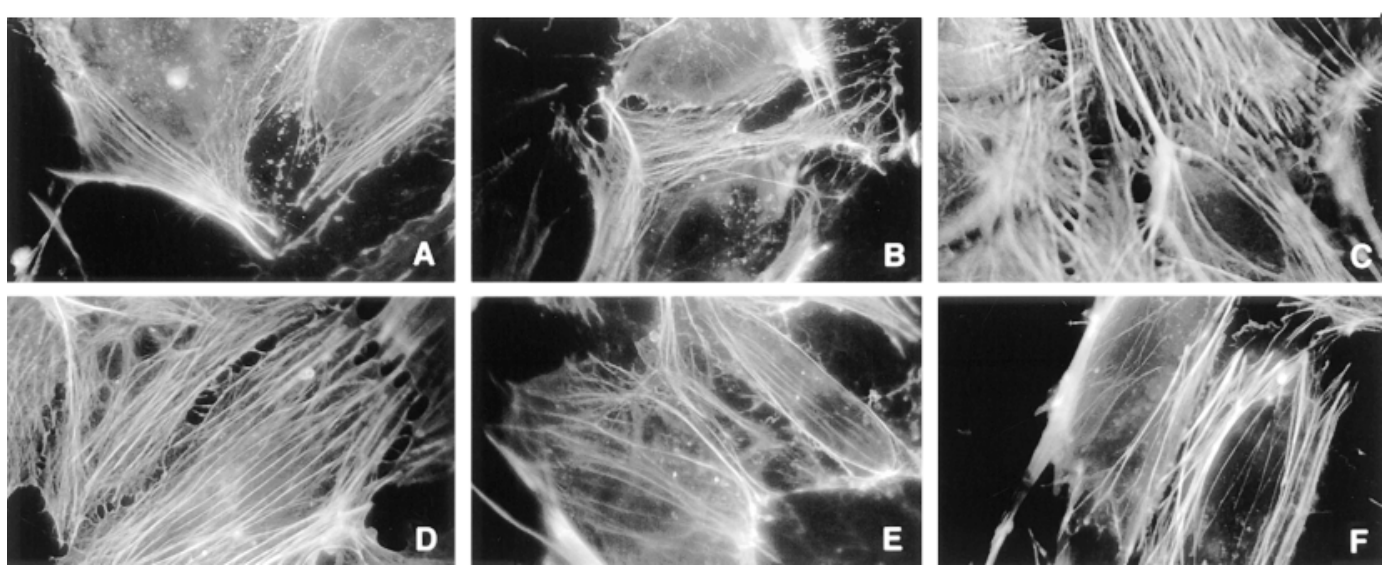

b
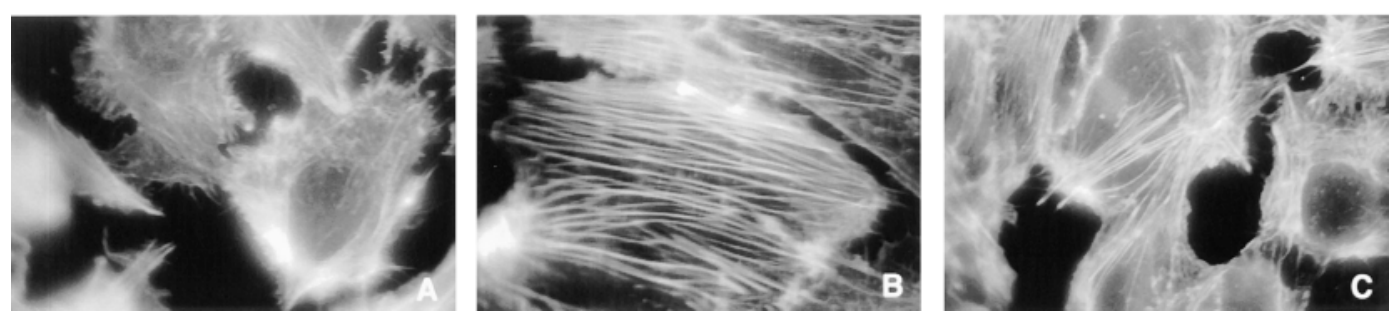

Figure 4. (a) F-actin distribution in cultured EC and the effects of FF or exogenous VEGF, $1 \mathrm{ng}$ / $\mathrm{ml}$. The white transverse lines represent phalloidin staining of the actin microfilaments. $A$ is EC cultured in media alone; $B$ is $\mathrm{EC}$ in the presence of group I FF; $C$ is group IV (high oocytes) FF; $D$ is exogenous VEGF, $1 \mathrm{ng}$; $E$ is exogenous VEGF plus VEGF antibody; $F$ is group IV FF plus VEGF antibody. A cortical (peripheral) distribution is seen in the control or low oocytes FF, but a transverse (stress fibers) distribution occurs in response to high oocyte FF or exogenous VEGF. Effects of FF or VEGF are substantially prevented by VEGF antibody. This study is representative of three separate studies. (b) Effect of L-NMMA on F-actin distribution induced by group IV FF. $A$ is EC cultured in media alone; $B$ is group IV FFincubated $\mathrm{EC}$; $C$ is group IV FF plus L-NMMA, 10 $\mu \mathrm{M}$. This study was repeated twice. 

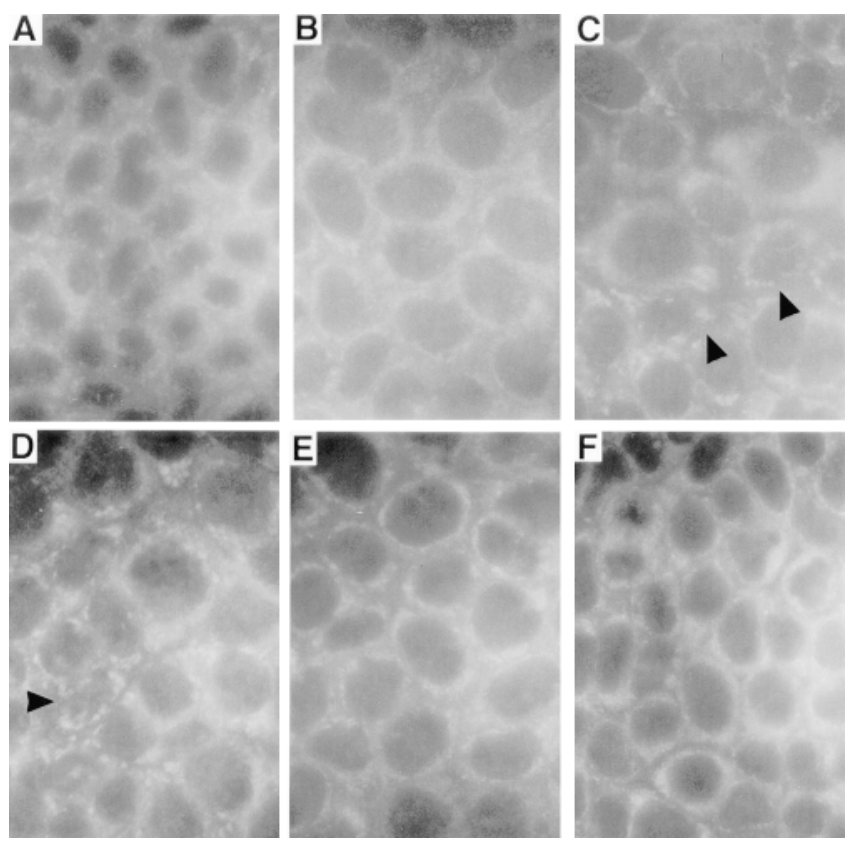

Figure 5. Distribution of the tight junction protein ZO-1 around apposed endothelial cells in response to FF or exogenous VEGF. Basal, discontinuous distribution of ZO- 1 in EC is shown in $A$. $B$ is EC in the presence of group I FF; $C$ is group IV (high oocytes) FF; $D$ is exogenous VEGF, $1 \mathrm{ng} / \mathrm{ml}$; $E$ is exogenous VEGF plus VEGF antibody; $F$ is group IV FF plus VEGF antibody. Arrowheads denote areas of typical ZO-1 disruption ( $C$ and $D$ ). This representative study was repeated twice.

mented by gonadotropic hormones administered as part of the fertility procedure (2-4); the factor is then secreted or is leaked from the massively enlarged ovaries. The resulting vascular permeability leads mainly to peritoneal fluid collection, edema, and occasionally hypovolemia. Loss of intravascular volume is largely responsible for the morbidity and occasional mortality associated with OHSS (3).

The development of this syndrome correlates well with the ovarian response to gonadotropic hormones. This response includes large numbers of stimulated follicles and increased serum estradiol (E2) levels, parameters that define patients at increased risk for developing this disorder $(26,27)$. Previous studies have correlated vasoactive substance levels in the vasculature or ovary with the temporal development of OHSS. As a result, various intra- and extra-ovarian substances have been postulated to contribute to OHSS, including prostaglandins, histamine, serotonin, prolactin, angiotensin, and interleukin-2 (28-33). Our results here implicate VEGF as the ovarian factor produced during hormonal induction, which directly leads to increased vascular permeability. VEGF is therefore likely to cause the manifestations of OHSS.

The actions of VEGF to enhance vascular permeability (6) may result in part from the effects of other vasoactive substances (34). Several actions of exogenous VEGF in vitro are partially dependent on the generation of NO from the target cell/organ, such as EC $(34,35)$. Our results indicate that the ability of the group IV FF to induce increased EC permeability is significantly, though not totally, dependent upon the generation of NO. We found similar dependance on NO for the permeability response to exogenous VEGF, supporting the find- ings of Murohara et al. (21). NO can induce increased vascular permeability through the activation of protein kinase $\mathrm{G}$ (36). NO can associate with and disrupt cytoskeletal protein complexing $(37,38)$ and can deplete ATP, leading to dilation of EC tight junctions (37) and the rearrangement of the actin cytoskeleton (39). The significant alterations of the cytoskeletal proteins of EC demonstrated in this study result in part from NO action.

The formation of the EC TJ modulates transendothelial solute exchange, and several proteins have been implicated in the dynamic formation of junctions. The association of TJ proteins (including ZO-1, ZO-2, and occludin) with both the actin cytoskeleton (40) and cadherin-catenin complex (41) are felt to play important roles (42). Disrupting EC tight junction protein complex formation results from the disorganization of the actin cytoskeleton $(43,44)$ and would lead to the endothelial fenestrations induced by VEGF (45). We believe this sequence of events underlies OHSS since we found that F-actin redistribution, formation of stress fibers, and ZO-1 protein destruction in response to group IV FF were each reversed by VEGF antibody. Recent in vitro studies showed that cadherin and occludin become disorganized at endothelial cell junctions in response to exogenous VEGF (46). Normally, complexing of ZO-1 proteins with occludin mediates occludin's localization to the tight junction and association with the cytoskeleton (25). VEGF-induced disruption of ZO-1 would 1) prevent this localization, and 2) markedly lower the electrical resistance of EC, resistance typifying an ionic barrier function (47).

Regarding the source of the permeability factor, VEGF transcripts and the protein isoforms VEGF121 and especially VEGF165 have been found in human ovarian tissue (15). Luteinized human ovarian granulosa cells, isolated from women undergoing hormonal stimulation for in vitro fertilization, express high concentrations of VEGF mRNA (16). In cultured bovine ovarian granulosa cells (GC), either LH or E2 can stimulate VEGF mRNA expression, but the effects of LH are more rapid (48). Cultured human GC respond to hCG with increased VEGF mRNA production (49); this leads us to speculate that in our patients there is a sequential action of the administered hormones (FSH, human menopausal gonadotropins, and hCG) to first directly stimulate VEGF production. This is followed by increased estrogen production that independently augments VEGF. High intraovarian levels of E2 are probably necessary for VEGF production and the clinical syndrome (50). Presumably, VEGF produced in the ovary acts locally, spills into the peritoneal cavity, and is also secreted into the blood. It has been shown that some women who develop OHSS have elevated levels of VEGF in their blood $(51,52)$, although the source of the VEGF is not clear, since vascular smooth muscle cells potently produce this growth factor. We found that ovarian FF contained the VEGF165 isoform by immunoblot. Since this same antibody blocked the ability of the FF to stimulate endothelial cell permeability, we propose that ovarian VEGF165 contributes to the clinical symptomatology.

Since increased vascular permeability also occurs at ovulation $(53,54)$, OHSS could be viewed as an exaggeration of the events that occur during the menstrual cycle. When this growth/permeability factor is produced in excess by the superphysiologic hormonal induction of ovulation, it can lead to the clinical syndrome of OHSS. Recently, Kobayashi et al. (55) measured low levels of VEGF in the ascites from three women with OHSS, concentrations that did not produce increased 
capillary permeability. This led them to conclude that VEGF may not be involved in the pathogenesis of this syndrome. In contrast, several studies have measured much higher concentrations of VEGF in the peritoneal fluid and/or serum of women who developed OHSS after fertility induction (50, 52, 56). In a previous study, peritoneal fluid from three women with OHSS induced increased capillary permeability, which was prevented by the VEGF antibody (57). There was no determination of the source of VEGF or mechanism of VEGF action. Our patients in group IV developed significant signs of OHSS, including edema and ascites, requiring bed rest and diuresis. Their FFs induced the greatest EC permeabilities, which were $98 \%$ reversed by the VEGF antibody. VEGF concentrations in the FF from the four group IV patients were more than three times those of group I patients, who were asymptomatic. Group IV individuals also produced the largest numbers of oocytes, and their FF caused EC cytoskeletal rearrangement, F-actin redistribution, and degradation of ZO-1 protein at the tight junction.

The collective data therefore supports an important role for VEGF in this syndrome. The increase in permeability stimulated by the FF from our patients was not linearly related to the absolute VEGF concentrations. This suggests that there is a threshold concentration of VEGF, which is necessary to induce EC permeability. It is difficult to definitively identify VEGF as the causative factor in vivo, because there is no VEGF receptor antagonist currently available. A naturally occurring truncated form of the VEGF receptor, flt, is an antagonist of some actions of VEGF (58), but its therapeutic use is unknown. We have recently demonstrated that stimulation of VEGF synthesis in cultured vascular smooth muscle cells is substantially inhibited by members of the natriuretic peptide family (59). Administration of these peptides might limit production of this growth factor in OHSS, potentially serving as a therapeutic approach in predisposed individuals.

In summary, FF from women undergoing hormonal ovarian stimulation significantly increased endothelial cell permeability, which correlated with the magnitude of oocyte production (an important index of the degree of stimulation). We have demonstrated that the FF factor responsible for increased EC permeability is VEGF and therefore is the likely factor leading to the important manifestations of OHSS. Rearrangement of the actin cytoskeleton and disruption of ZO-1 protein is a likely primary mechanism by which VEGF in the FF disrupts the EC tight junctions and increases permeability. Receptor antagonists or inhibitors of VEGF synthesis should prove useful in preventing the development of this disorder.

\section{Acknowledgments}

We would like to thank Dr. Rick Kendall (Merck Inc.) for providing VEGF protein and helpful discussions. This work was supported by grants from the Research Service of the Veteran's Administration, and the National Institutes of Health (NS-30521) to E.R. Levin.

\section{References} 1112.

1. Editorial. 1991. Ovarian hyper stimulation syndrome. Lancet. 337:1111-

2. Polishuk, W.Z., and J.G. Schenker. 1969. Ovarian hyperstimulation syndrome. Fertil. Steril. 20:443-450.

3. Schenker, J., and D. Weinstein. 1978. Ovarian hyperstimulation syn- drome: a current survey. Fertil. Steril. 30:225-267.

4. Haning, R., Jr., E. Strawn, and W. Nolten.1985. Pathophysiology of the ovarian hyperstimulation syndrome. Obstet. Gynecol. 166:220-224.

5. Goldsman, M., A. Pedram, C. Dominguez, I. Ciuffardi, E. Levin, and R.H. Asch. 1995. Increased capillary permeability induced by human follicular fluid: a hypothesis for an ovarian origin of the hyperstimulation syndrome. Fertil. Steril. 63:268-272.

6. Senger, D.R., S.J. Galli, A.M. Dvorak, C.A. Peruzzi, V.S. Harvey, and H.F. Dvorak. 1983. Tumor cells secrete a vascular permeability factor that promotes accumulation of ascites fluid. Science. 219:983-985.

7. Milton, S.G., and K.P. Knutson. 1990. Comparison of the function of the tight junctions of the endothelial cells and epithelial cells in regulating the movement of electrolytes and macromolecules across the cell monolayer. $J$. Cell. Physiol. 144:498-504.

8. Larson, D.M. 1988. Intercellular junctions and junctional transfer in the blood vessel wall. In Endothelial Cells. Vol III. U.S. Ryan, editor. CRC Press, Boca Raton, FL. 75-84.

9. Keck, P.J., S.D. Hauser, G. Krivi, K. Sanzo, T. Warren, J. Feder, and D.T. Connolly. 1989. Vascular permeability factor, an endothelial cell mitogen related to PDGF. Science. 246:1309-1312.

10. Aiello, L.P., R.L. Avery, P.G. Arrigg, B.A. Keyt, H.D. Jampel, S.T. Shah, L.R. Pasquale, H. Thieme, M.A. Iwamoto, J.E. Park, et al. 1994. Vascular endothelial cell growth factor in ocular fluid of patients with diabetic retinopathy and other retinal disorders. N. Engl. J. Med. 331:1480-1487.

11. Kim, K.J., B. Li, J. Winer, M. Armanini, N. Gillett, H.S. Phillips, and N. Ferrara. 1993. Inhibition of vascular endothelial cell growth factor-induced angiogenesis suppresses tumor growth in vivo. Nature. 362:841-844.

12. Millauer, B., L.K. Shawver, K.H. Plate, W. Risau, and A. Ullrich. 1994 Glioblastoma growth inhibited in vivo by a dominant negative Flk-1 mutant. Nature. 367:576-579.

13. Terman, B.I., M. Dougher-Vermazen, M.E. Carrion, D. Dimitrov, D.C. Armellino, D. Gospodarowicz, and P. Böhlen. 1992. Identification of the KDR tyrosine kinase as a receptor for vascular endothelial cell growth factor. Biochem. Biophys. Res. Commun. 187:1579-1586.

14. deVries, C., J.A. Escobedo, H. Ueno, K. Houck, N. Ferrarra, and L.T. Williams. 1992. The fms-like tyrosine kinase, a receptor for vascular endothelial cell growth factor. Science. 255:989-991.

15. Olson, T.A., D. Mohanraj, L.F. Carson, and S. Ramakrishnan. 1994. Vascular permeability factor gene expression in normal and neoplastic human ovaries. Cancer Res. 54:276-280.

16. Yan, Z., H.A. Weich, W. Bernart, M. Breckwoldt, and J. Neulen. 1993. Vascular endothelial cell growth factor (VEGF) messenger ribonucleic acid (mRNA) expression in luteinized human granulosa cells in vitro. J. Clin. Endocrinol. Metab. 77:1723-1725.

17. Prins, B., R.M. Hu, B. Nazario, A. Pedram, H.J.L. Frank, M. Weber, and E.R. Levin. 1994. Prostaglandin $\mathrm{E}_{2}$ and prostacyclin inhibit the production and secretion of endothelin from cultured endothelial cells. J. Biol. Chem. 269: $11938-11944$.

18. Ma, T.Y., D. Hollander, D. Bhalla, H. Nguyen, and P. Krugliak. 1992. IEC-18 $\alpha$ nontransfromed small intestinal cell line for studying epithelial permeability. J. Lab. Clin. Med. 120:329-341.

19. Levin, E.R. 1988. Atrial natriuretic factor is detectable in human cerebrospinal fluid. J. Clin. Endocrinol. Metab. 66:1080-1083.

20. Hu, R.M., E.R. Levin, A. Pedram, and H.J.L. Frank. 1992. Atrial natriuretic peptide inhibits the translation and secretion of endothelin from cultured bovine aortic endothelial cells: mediation through C receptors. J. Biol. Chem. 267:17384-17389.

21. Murohara, T., J.R. Horowitz, M. Silver, Y. Tsurumi, D. Chen, A. Sullivan, and J.M. Isner. 1998. Vascular endothelial growth factor/vascular permeability factor enhances vascular permeability via nitric oxide and prostacyclin. Circulation. 97:99-107.

22. Ferrara, N., J. Winer, and T. Burton. 1991. Aortic smooth muscle cells express and secrete vascular endothelial cell growth factor. Growth Factors. 5: 141-148.

23. Schneeberger, E.E., and R.D. Lynch. 1992. Structure, function, and regulation of cellular tight junctions. Am. J. Physiol. 262:L647-L661.

24. Barry, P.A., W.M. Petroll, P.M. Andrews, H.D. Cavanagh, and J.V Jester. 1995. The spatial organization of corneal endothelial cytoskeletal proteins and their relationship to the apical junctional complex. Invest. Ophthalmol. Vis. Sci. 36:1115-1124.

25. Furuse, M., M. Itoh, T. Hirase, A. Nagafuchi, S. Yonemura, and S. Tsukita. 1994. Direct association of occludin with ZO-1 and its possible involvement in the localization of occludin at tight junctions. J. Cell Biol. 127:16171626.

26. Haning, R.V., Jr., C.W. Austin, I.H. Carlson, D.L. Kuzma, S.S. Shapiro, and W.J. Zweibel. 1983. Plasma estradiol is superior to ultrasound and urinary estriol glucuronide as a predictor of ovarian hyperstimulation during induction of ovulation with menotropins. Fertil. Steril. 40:31-36.

27. Asch, R.H., H.P. Li, J.P. Balmaceda, L.N. Weckstein, and S.C. Stone. 1991. Severe ovarian hyperstimulation syndrome in assisted reproductive technology: definition of high risk groups. Hum. Reprod. 6:1395-1399.

28. Schenker, J., and W. Polishuk. 1976. The role of prostaglandins in the 
hyperstimulation syndrome. Eur. J. Obstet. Gynecol. Reprod. Biol. 6:47-52.

29. Pride, S., B. Yuen, and Y. Moon. 1984. Clinical, endocrinologic and intraovarian prostaglandin responses to $\mathrm{H} 1$ receptor blockade in the ovarian hyperstimulation syndrome: studies in the rabbit model. Am. J. Obstet. Gynecol. 148:670-674.

30. Zaidse, I., M. Friedman, E. Lindembaum, R. Askenazi, B. Peretz, and E. Paldi. 1983. Serotonin and the ovarian hyperstimulation syndrome. Eur. J. Obstet. Gynecol. Reprod. Biol. 15:55-60.

31. Leung, P., B. Yuen, and Y. Moon. 1983. Effect of prolactin in an experimental model of the ovarian hyperstimulation syndrome. Am. J. Obstet. Gynecol. 143:847-859.

32. Navot, D., E.J. Margalioth, N. Laufer, A. Brzezinski, A. Birkenfeld, and J.G. Schenker. 1987. Direct correlation between plasma renin activity and severity of the ovarian hyperstimulation syndrome. Fertil. Steril. 48:57-61.

33. Orvieto, R., I. Voliovitch, P. Fishman, and Z. Ben-Rafael. 1995. Interleukin-2 and ovarian hyperstimulation syndrome: a pilot study. Hum. Reprod. 10:24-27.

34. Wu, H.M., H. Qiaobing, Y. Yuan, and H.J. Granger. 1996. VEGF induces NO-dependent hyperpermeability in coronary venules. Am. J. Physiol. 271:H2735-H2739.

35. Ziche, M., L. Morbidelli, R. Choudhuri, H.T. Zhang, S. Donnini, H.J. Granger, and R. Bicknell. 1997. Nitric oxide synthase lies downstream of vascular endothelial cell growth factor-induced but not fibroblast growth factorinduced angiogenesis. J. Clin. Invest. 11:2625-2634.

36. Venema, V.J., M.B. Marrero, and R.C. Venema. 1996. Bradykinin-stimulated protein tyrosine kinase phosphorylation promotes endothelial nitric oxide synthase translocation to the nucleus. Biochem. Biophys. Res. Commun. 226:703-710.

37. Clancy, R.M., J. Rediske, X. Tang, N. Nijher, S. Frenkel, M. Philips, and S.B. Abramson. 1997. Outside-in signaling in the chondrocyte. Nitric oxide disrupts fibronectin-induced assembly of a subplasmalemmal actin/rho A/focal adhesion kinase signaling complex. J. Clin. Invest. 100:1789-1796.

38. Salzman, A.L., M.J. Menconi, N. Unno, R.M. Ezzell, D.M. Casey, P.K. Gonzalez, and M.P. Fink. 1995. Nitric oxide dilates tight junctions and depletes ATP in cultured Caco-2BBe intestinal epithelial monolayers. Am. J. Physiol. 268:G361-G373.

39. Bacallao, R., A. Garfinkel, S. Monke, G. Zampighi, and L.J. Mandel. 1994. ATP depletion: a novel method to study junctional properties in epithelial tissues. I. Rearrangement of the actin cytoskeleton. J. Cell Sci. 107:3301-3313.

40. Gumbiner, B.M. 1996. Cell adhesion: the molecular basis of tissue architecture and morphogenesis. Cell. 84:345-357.

41. Haselton, F.R., and R.L. Heimark. 1997. Role of cadherins 5 and 13 in the aortic endothelial barrier. J. Cell. Physiol. 171:243-251.

42. Tsukamoto, T., and S.K. Nigam. 1997. Tight junction proteins form large complexes and associate with the cytoskeleton in an ATP depletion model for reversible junction assembly. J. Biol. Chem. 272:16133-16139.

43. Bacallao, R., A. Garfinkel, S. Monke, G. Zampighi, and L.J. Mandel. 1994. ATP depletion: a novel method to study junctional properties in epithelial tissues. I. Rearrangement of the actin cytoskeleton. J. Cell Sci. 107:3301-3313.

44. Kwon, O., W.J. Nelson, R. Sibley, P. Huie, J.D. Scandling, D. Dafoe, E. Alfrey, and B.D. Myers. 1998. Backleak, tight junctions, and cell-cell adhesion in postischemic injury to the renal allograft. J. Clin. Invest. 101:2054-2064.

45. Roberts, W.G., and G.E. Palade. 1995. Increased microvascular permeability and endothelial fenestration induced by vascular endothelial growth factor. J. Cell Sci. 108:2369-2379.

46. Kevil, C.G., D.K. Paynes, E. Mire, and J.S. Alexander. 1998. Vascular permeability factor/vascular endothelial cell growth factor-mediated permeability occurs through disorganization of endothelial junctional proteins. $J$. Biol. Chem. 273:15099-15103.

47. Blum, M.S., E. Toninelli, J.M. Anderson, M.S. Balda, J. Zhou, L. O'Donnell, R. Pardi, and J.R. Bender. 1997. Cytoskeletal rearrangement mediates human microvascular endothelial tight junction modulation by cytokines. Am. J. Physiol. 273:H286-H294.

48. Garrido, C., S. Saule, and D. Gospodarowicz. 1993. Transcriptional regulation of vascular endothelial cell growth factor gene expression in ovarian bovine granulosa cells. Growth Factors. 8:109-117.

49. Neulen, J., Y. Yan, S. Raczek, K. Weindel, C. Keck, H.A. Weich, D. Marmé, and M. Breckwoldt. 1995. Human chorionic gonadotropin-dependent expression of vascular endothelial growth factor/vascular permeability factor in human granulosa cells: importance in ovarian hyperstimulation syndrome. $J$. Clin. Endocrinol. Metab. 80:1967-1971.

50. Krasnow, J.S., S.L. Berga, D.S. Guzick, A.J. Zeleznik, and K.T. Yeo. 1996. Vascular permeability factor and vascular endothelial growth factor in ovarian hyperstimulation syndrome: a preliminary report. Fertil. Steril. 65:552555 .

51. Pride, S.M., C. James, and B. Yuen. 1990. The ovarian hyperstimulation syndrome. Semin. Reprod. Med. 8:247-259.

52. Abramov, Y., V. Barak, B. Nisman, and J.G. Schenker. 1997. Vascular endothelial cell growth factor plasma levels correlate to the clinical picture in severe ovarian hyperstimulation syndrome. Fertil. Steril. 67:261-265.

53. Bassett, D.L. 1943. The changes in the vascular pattern of the ovary of the albino rat during estrus cycle. Am. J. Anat. 73:251-291.

54. Cavender, J.L., and W.J. Murdoch. 1988. Morphological studies of the microcirculatory system of periovulatory ovine follicles. Biol. Reprod. 39:989997.

55. Kobayashi, H., Y. Okada, T. Asahina, J. Gotoh, and T. Terao. 1998. The kallikrein-kinin system, but not vascular endothelial cell growth factor, plays a role in the increased vascular permability associated with ovarian hyperstimulation syndrome. J. Mol. Endcocrinol. 20:363-374.

56. Lee, A., L.K. Christenson, R.L. Stouffer, K.A. Burry, and P.E. Patton. 1997. Vascular endothelial cell growth factor levels in serum and follicular fluid of patients undergoing in vitro fertilization. Fertil. Steril. 68:305-311.

57. McClure, N., D.L. Healy, and P.A.W. Rogers. 1994. Vascular endothelial cell growth factor as permeability agent in ovarian hyperstimulation syndrome. Lancet. 344:235-236.

58. Kendall, R.L., and K.A. Thomas. 1993. Inhibition of vascular endothelial cell growth factor activity by an endogenously encoded soluble receptor. Proc. Natl. Acad. Sci. USA. 90:10705-10709.

59. Pedram, A., M. Razandi, R.M. Hu, and E.R. Levin. 1997. Vasoactive peptides modulate vascular endothelial cell growth factor production and endothelial cell proliferation and invasion. J. Biol. Chem. 272:17097-17103. 